\title{
Chromosome painting in three-toed sloths: a cytogenetic signature and ancestral karyotype for Xenarthra
}

\author{
Nathália F Azevedo ${ }^{1 \dagger}$, Marta Svartman ${ }^{2+}$, Andrea Manchester ${ }^{1}$, Nádia de Moraes-Barros ${ }^{1}$, Roscoe Stanyon ${ }^{3}$ and \\ Angela M Vianna-Morgante ${ }^{1 *}$
}

\begin{abstract}
Background: Xenarthra (sloths, armadillos and anteaters) represent one of four currently recognized Eutherian mammal supraorders. Some phylogenomic studies point to the possibility of Xenarthra being at the base of the Eutherian tree, together or not with the supraorder Afrotheria. We performed painting with human autosomes and X-chromosome specific probes on metaphases of two three-toed sloths: Bradypus torquatus and B. variegatus. These species represent the fourth of the five extant Xenarthra families to be studied with this approach.

Results: Eleven human chromosomes were conserved as one block in both B. torquatus and B. variegatus: (HSA 5, $6,9,11,13,14,15,17,18,20,21$ and the $X$ chromosome). B. torquatus, three additional human chromosomes were conserved intact (HSA 1, 3 and 4). The remaining human chromosomes were represented by two or three segments on each sloth. Seven associations between human chromosomes were detected in the karyotypes of both B. torquatus and B. variegatus: HSA 3/21, 4/8, 7/10, 7/16, 12/22, 14/15 and 17/19. The ancestral Eutherian association 16/19 was not detected in the Bradypus species.

Conclusions: Our results together with previous reports enabled us to propose a hypothetical ancestral Xenarthran karyotype with 48 chromosomes that would differ from the proposed ancestral Eutherian karyotype by the presence of the association HSA 7/10 and by the split of HSA 8 into three blocks, instead of the two found in the Eutherian ancestor. These same chromosome features point to the monophyly of Xenarthra, making this the second supraorder of placental mammals to have a chromosome signature supporting its monophyly.
\end{abstract}

\section{Background}

Xenarthra, which reunites sloths, armadillos and anteaters, is one of the four currently recognized Eutherian mammal supraorders, together with Afrotheria, Euarchontoglires and Laurasiatheria. The group has as its main morphological synapomorphy used to name it the presence of xenarthrous vertebrae, additional articulations between the dorsal and lumbar vertebrae [1]. Morphological and molecular data support the monophyly of Xenarthra [2-7], which is composed of two living orders: Cingulata, formed by the family Dasypodidae, with 21

\footnotetext{
* Correspondence: avmorgan@ib.usp.br

† Contributed equally

'Departamento de Genética e Biologia Evolutiva, Instituto de Biociências, Universidade de São Paulo, Rua do Matão 277, Cidade Universitária, São

Paulo, SP 05408-090, Brazil

Full list of author information is available at the end of the article
}

species of armadillos; and Pilosa, composed by the suborders Vermilingua, with two families - Cyclopedidae and Myrmecophagidae, and four species of anteaters, and Folivora, with two families - Bradypodidae and Megalonychidae, and six species of sloths [8] (Figure 1).

Xenarthra has lately been the focus of interest because of its possible position at the base of the Eutherian phylogenetic tree. Phylogenies based on morphological data and some molecular studies put Xenarthra at the base of the tree [9]. A second hypothesis, supported by molecular data, puts Afrotheria in the most basal position $[6,10-14]$. A third possibility, mainly based on molecular analyses and phylogenomics, considers Afrotheria and Xenarthra as sister-groups, forming the clade Atlantogenata, which would be on the base of the Eutherian tree [3,15-21].

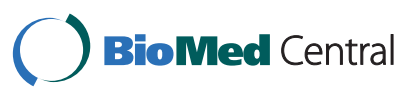




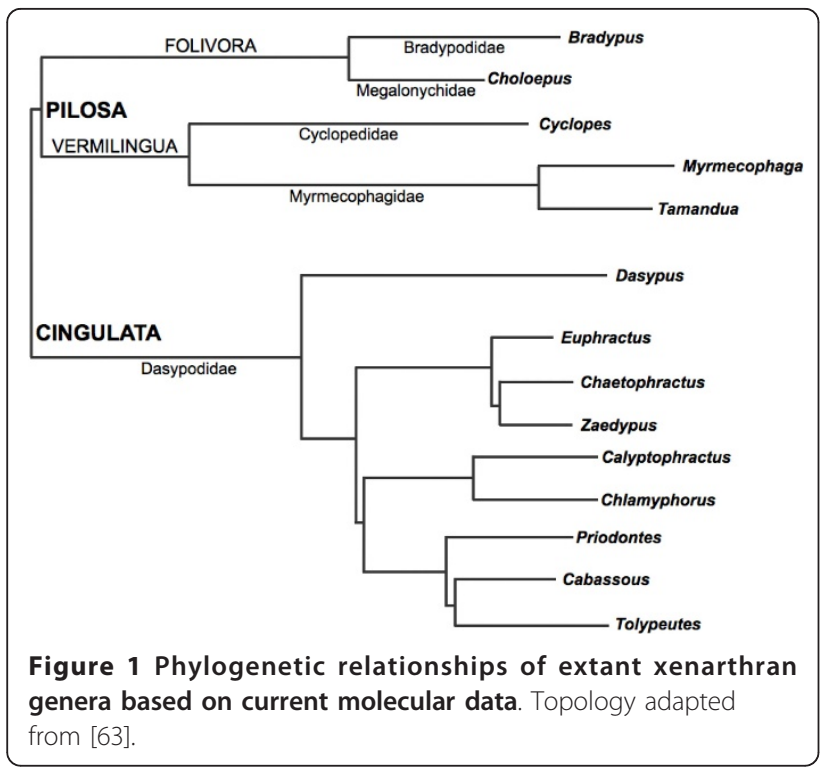

\section{Extant species of sloths}

The living species of sloths are grouped into two families [8]. Megalonychidae or the two-toed sloths are represented by a single genus, Choloepus, and two species, C. hoffmanni and C. didactylus. This family is restricted to the Neotropical forests of Central America and northern South America [22]. Bradypodidae or three-toed sloths reunites the four species of the genus Bradypus. B. variegatus is found in the Amazon and in the Brazilian Atlantic forest, Caatinga and Cerrado biomes. B. torquatus is endemic to the Brazilian Atlantic forest, B. tridactylus lives in the Amazon [22] and the recently described $B$. pygmaeus is endemic to the island of Escudo de Veraguas, on the Caribbean coast of Panama [23]. According to the red list of the International Union for Conservation of Nature [24], two sloth species are included in a threatened category; $B$. pygmaeus is listed as critically endangered with decreasing population size, and $B$. torquatus is a vulnerable species due to the degradation and fragmentation of the area where it occurs, the Atlantic forest.

While the monophyly of Folivora (sloths) is highly supported, detailed analyses within the sloth clade indicated the diphyletic origin of Choloepus and Bradypus [3,25-27].

\section{Cytogenetics of Xenarthra}

The chromosomes of Xenarthra are still poorly studied and most of the described karyotypes were analyzed after conventional staining, without banding patterns [28-30]. The diploid numbers in Xenarthra range from $2 \mathrm{n}=38$ in the armadillo Tolypeutes matacus to $2 \mathrm{n}=65$ in the sloth Choloepus didactylus [29,31]. The diploid numbers range from $2 n=54$ to $2 n=64$ in the anteaters and from $2 \mathrm{n}=38$ to $2 \mathrm{n}=64$ in the armadillos [29,30,32].

In sloths, karyotypic studies showed a complex picture. The karyotypes described for the genus Choloepus have a diploid number ranging from $2 n=49$ to $2 n=$ 65 , which may actually belong to cryptic species not identified as yet [31,33-36] and Y/autosome translocations have been reported in Choloepus hoffmanni with $2 \mathrm{n}=49$ [37] and in C. didactylus with $2 \mathrm{n}=65$ [31]. The diploid numbers of Bradypus species are better characterized: Bradypus torquatus showed $2 \mathrm{n}=50$ [38,39], Bradypus variegatus had $2 \mathrm{n}=54[34,38,40]$ and Bradypus tridactylus had $2 \mathrm{n}=52[31,33]$. The karyotype of B. pygmaeus has not been described.

\section{Molecular cytogenetics and chromosome painting}

Chromosome painting is a very useful tool in phylogenetic studies because chromosome rearrangements are considered rare genomic changes with low levels of homoplasy [41]. The resolution of the technique is sufficient to allow the reconstruction of lineages that show relationships among species, families and orders, often revealing characteristic chromosome signatures of each lineage [42]. Based on interspecific chromosomal painting using human chromosomes as probes, there are currently two main proposals for a hypothetical ancestral Eutherian karyotype (AEK). An AEK with $2 \mathrm{n}=48$ would be composed of human chromosomes HSA 1, 2p, 2q, 3/21, 4/8p, 5, 6, 7a, 7b/16p, 8q, 9, 10p, 10q, 11, 12/ 22 twice, 13, 14/15, 16q/19q, 17, 18, 19p, 20 and $X$ $[43,44]$. Alternatively, an AEK with $2 n=46$, differing only by an additional association HSA 10p/12/22, has also been suggested (reviewed in [42]).

Painting with human chromosome has been performed in three of the five recognized families of Xenarthra: in the lesser anteater (Tamandua tetradactyla), in two species of two-toed sloths (Choloepus didactylus and C. hoffmanni), and in two species of armadillos (Dasypus novemcinctus and Euphractus sexcinctus) $[36,45,46]$. In this work, we performed painting with human chromosome-specific probes in two species of three-toed sloths: Bradypus torquatus and B. variegatus. These species represent the fourth family of Xenarthra analyzed with this approach, which enabled us to hypothesize on an ancestral Xenarthran karyotype and to compare it to the putative ancestral Eutherian complement. Our data also allowed us to discuss chromosome signatures supporting the subordinal levels of classification in Xenarthra and Folivora phylogeny.

\section{Results}

\section{B. torquatus}

Interspecies hybridization results were obtained for all the human probes except the $\mathrm{Y}$ in $B$. torquatus 
chromosomes (BTO). A total of 32 conserved segments between human (HSA) and BTO were observed (Figure 2a; Table 1). Fifteen human chromosomes hybridized to a single sloth chromosome or chromosome segment (HSA 1, 3, 4, 5, 6, 9, 11, 13, 14, 15, 17, 18, 20, 21 and the $\mathrm{X}$ chromosome). Seven human chromosomes (HSA $2,7,10,12,16,19$ and 22) labeled two segments each on the sloth karyotype and HSA 8 produced three hybridizations signals in B. torquatus. Seven associations between human chromosomes were detected in the karyotype of B. torquatus: HSA 3/21, 4/8, 7/10, 7/16, 12/22 (twice), $14 / 15$ and $17 / 19$. Some examples of the hybridization experiments are depicted in Figure 3.

No hybridization signals were observed on the pericentromeric regions of the sloth chromosomes. Chromosome BTO23, the short arms of BTO1 and BTO4, and a small proximal segment on the long arm of BTO1 were not labeled by any of the human chromosome probes (Figure 2a). Except for BTO 23, these unlabeled regions corresponded to constitutive heterochromatin as revealed by $\mathrm{C}$-banding (Figure $2 \mathrm{~b}$ ).

\section{B. variegatus}

With the exception of HSA 21, the human autosomal and $\mathrm{X}$ chromosome probes hybridized to the $B$. variegatus chromosomes (BVA), yielding a total of 35 conserved segments (Figure 4a; Table 1). The results of some hybridization experiments are shown in Figure 5. Eleven human chromosomes (HSA 5, 6, 9, 11, 13, 14, $15,17,18,20$ and the $\mathrm{X}$ ) hybridized to a single sloth chromosome or chromosome segment and nine human chromosomes (HSA 1, 2, 3, 4, 7, 10, 12, 19 and 22) labeled two segments in different sloth chromosomes
Three hybridization signals were obtained on the sloth karyotype after hybridization of HSA 8. HSA 16 also labeled three BVA segments, but two of them on the same chromosome. Seven associations between human chromosomes were observed on the karyotype of $B$. variegatus: HSA 4/8, 7/10, 7/16, 12/22, 12/22/16, 14/15 and $17 / 19$. We could not get hybridization results with the HSA 21 probe and thus the ancestral association HSA $3 / 21$ could not be observed in this species. Nevertheless, it is very likely present on chromosome BVA 1 , which was proximally labeled by HSA 3 and had a non-heterochromatic distal segment unlabeled by any human chromosome probe. Besides, after G-banding, BVA1 seems to correspond to BTO 2, which in turn is homologous to HSA $3 / 21$. If these conclusions are accurate, a total of 36 , instead of 35 , conserved segments are present in the complement of $B$. variegatus after painting with human chromosomes.

No hybridization signals were observed on the pericentromeric regions of the BVA chromosomes, neither were the proximal segments of the short and long arms of BVA 18 or the entire BVA 25 labeled by any human probe (Figure 4a). Excepting for BVA 25, these segments were heterochromatic as revealed by $\mathrm{C}$-banding (Figure $4 \mathrm{~b}$ ).

\section{Discussion}

Our data on chromosome painting with human probes in two three-toed sloth species, Bradypus torquatus ( $2 \mathrm{n}$ $=50)$ and $B$. variegatus $(2 \mathrm{n}=54)$ raises to four the number of Xenarthra families studied with this approach, leaving only the chromosomes of the monospecific family Cyclopedidae to be analyzed after chromosome painting with human probes.
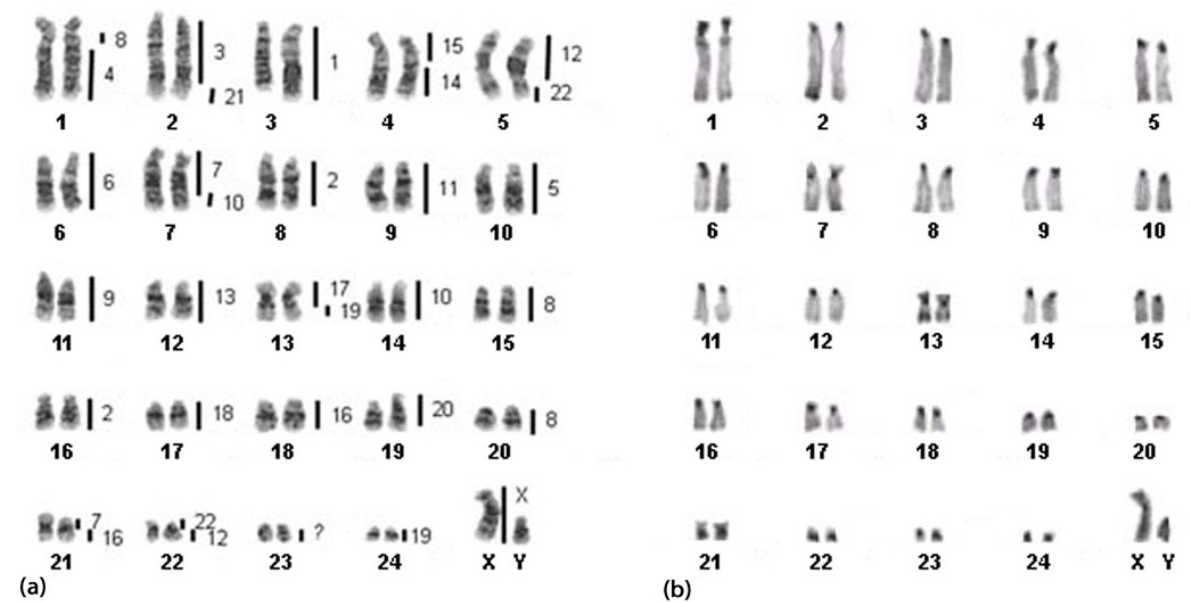

Figure 2 Correspondence between human chromosomes and (a) the G-banded karyotype of a male Bradypus torquatus ( $2 \mathrm{n}=50$ ); (b) C-banded karyotype of a male Bradypus torquatus. Each sloth chromosome segment was painted by the human chromosome indicated to the right. 
Table 1 Correspondence between human and Xenarthran chromosomes based on chromosome painting with human probes

\begin{tabular}{|c|c|c|c|c|c|}
\hline \multirow[t]{2}{*}{ Species } & \multirow[t]{2}{*}{ Associations of human autosomes } & \multicolumn{3}{|c|}{ Human Chromosomes } & \multirow[t]{2}{*}{ Reference } \\
\hline & & Conserved & Two blocks & $\begin{array}{c}\text { Three or } \\
\text { more } \\
\text { blocks }\end{array}$ & \\
\hline $\begin{array}{l}\text { Bradypus } \\
\text { torquatus } \\
(2 n=50)\end{array}$ & $3 / 21,4 / 8,7 / 10,7 / 16,12 / 22(2 x), 14 / 15,17 / 19$ & $\begin{array}{c}1,3,4,5,6,9,11,13,14 \\
15,17,18,20,21, x\end{array}$ & $\begin{array}{c}2,7,10,12,16,19 \\
22\end{array}$ & 8 & This work \\
\hline $\begin{array}{l}\text { Bradypus } \\
\text { variegates } \\
(2 n=54)\end{array}$ & $3 / 21 ?, 4 / 8,7 / 10,7 / 16,12 / 22,12 / 22 / 16,14 / 15,17 / 19$ & $\begin{array}{c}5,6,9,11,13,14,15,17 \\
18,20,21 ?, x\end{array}$ & $\begin{array}{c}1,2,3,4,7,10,12 \\
19,22\end{array}$ & 8,16 & This work \\
\hline $\begin{array}{l}\text { Bradypus } \\
\text { tridactylus } \\
(2 n=52)\end{array}$ & $2 / 6,3 / 21,4 / 8,7 / 10,7 / 16,11 / 19,12 / 22,12 / 22 / 16$ & $\begin{array}{c}1,5,9,11,13,14,15,17 \\
18,20,21, x\end{array}$ & $\begin{array}{c}2,3,4,7,10,12,16 \\
19,22\end{array}$ & $6,8 ?$ & $\begin{array}{l}\text { inferred } \\
\text { from } \\
{[31,46]}\end{array}$ \\
\hline $\begin{array}{l}\text { Choloepus } \\
\text { hoffmanni } \\
(2 n=50)\end{array}$ & $3 / 21,4 / 8,7 / 16,12 / 22(2 x), 14 / 15,16 / 19$ & $\begin{array}{c}1,3,4,5,6,9,10,11,13 \\
14,15,17,18,20,21, x\end{array}$ & $2,7,12,19,22$ & $8 ?, 16$ & [36] \\
\hline $\begin{array}{l}\text { Choloepus } \\
\text { didactylus } \\
(2 n=65)\end{array}$ & $2 / 8,3 / 21,4 / 8,7 / 10,7 / 16,12 / 22(2 x), 14 / 15$ & $9,13,15,17,18,20,21, x$ & $\begin{array}{l}1,3,4,5,6,10,11 \\
12,14,16,19,22\end{array}$ & $2,7,8$ & {$[46]$} \\
\hline $\begin{array}{c}\text { Dasypus } \\
\text { novemcinctus } \\
(2 n=64)\end{array}$ & $3 / 21(2 x), 4 / 8,7 / 16,10 / 12,12 / 22(2 x), 14 / 15,16 / 19$ & $\begin{array}{c}5,9,13,14,15,17,18,20 \\
x\end{array}$ & $\begin{array}{l}1,4,6,7,10,11,16 \\
19 ?, 21,22\end{array}$ & $2 ?, 3,8,12$ & {$[36]$} \\
\hline $\begin{array}{l}\text { Euphractus } \\
\text { sexcinctus } \\
(2 n=58)\end{array}$ & $2 / 8,3 / 21,4 / 8,7 / 10,7 / 16,12 / 22(2 x), 14 / 15,16 / 19$ & $\begin{array}{c}5,9,13,14,15,17,18,20 \\
21, X\end{array}$ & $\begin{array}{c}1,6,7,10,11,16 \\
19,22\end{array}$ & $2,3,4,8,12$ & [45] \\
\hline $\begin{array}{c}\text { Tamandua } \\
\text { tetradactyla } \\
(2 n=54)\end{array}$ & $\begin{array}{c}1 / 9,1 / 13,1 / 19,2 / 8,3 / 6,3 / 21,4 / 8,7 / 16,8 / 17,12 / 22 \\
(2 x), 14 / 15(2 x), 16 / 19,3 / 22,5 / 11,7 / 20,20 / 7 / 10\end{array}$ & $9,10,13,17,18,20,21, x$ & $\begin{array}{l}2,6,7,11,12,14 \\
15,16,19,22\end{array}$ & $1,3,4,5,8$ & {$[36,46]$} \\
\hline
\end{tabular}

The three-toed sloth Bradypus tridactylus $(2 \mathrm{n}=52)$ had its chromosomes painted with chromosome-specific probes from the two-toed sloth Choloepus didactylus (CDI) [31] and human chromosome probes were hybridized to the chromosomes of CDI [46]. Except for CDI 18, 20 and 30, which correspond, respectively, to HSA 2/8, 14 and 11, all CDI probes labeled chromosome segments in B. tridactylus. These results allowed us to infer the correspondence between the human chromosomes and those of B. tridactylus (Figure 6a; Table 1). In B. tridactylus, at least 35 segments would result from chromosome painting with human probes (Figure 6a).

Painting with human chromosome-specific probes revealed features common to the karyotypes of the two sloth species studied herein and also in the inferred human painted karyotype of $B$. tridactylus (Table 1; Figure 6a): (a) the associations HSA $3 / 21,4 / 8,7 / 10,7 / 16$, $12 / 22,14 / 15$ and $17 / 19$, (b) the conservation of HSA 5 , 9, 11, 13, 14, 15, 17, 18, 20 and X, (c) two pairs labeled by HSA 2, 7, 10, 12, 19 and 22 . In addition, the ancestral association HSA 16/19, present in most Eutherians, was absent in the three-toed sloths. HSA 8 was divided into three segments in B. torquatus and B. variegatus, as already shown in all the other Xenarthra species analyzed so far $[36,45,46]$, with the exception of B. tridactylus. Nevertheless, the CDI 18 probe, which corresponds to HSA $2 / 8$, did not hybridize in $B$. tridactylus [31] and it is thus likely that HSA 8 is also divided into three blocks in this species.

The HSA 17/19 association present in the three Bradypus species has not been found in any other species of Eutheria. We thus propose that this association represents a chromosome signature of the genus Bradypus, supporting the monophyly of the group, already indicated by molecular data [47].

The conservation of HSA 1 as only one chromosome and the split of HSA 16 in two blocks are shared by $B$. tridactylus and B. torquatus and are present in the proposed Eutherian ancestral karyotypes, representing thus symplesiomorphies. On the other hand, the presence of HSA 3 and 4 in two blocks and of the association HSA $12 / 22 / 16$, common to B. variegatus and B. tridactylus, are derived characteristics, absent in the ancestral karyotype. The fission of HSA 3 and 4 was already reported in other species of Eutheria, including Xenarthra $[36,46,48,49]$, but the HSA $12 / 22 / 16$ association was not observed in any other Xenarthra species or outgroup. We thus suggest that this association represents a chromosome synapomorphy common to $B$. variegatus and B. tridactylus. Reciprocal chromosome painting would allow the precise identification of the chromosome segments involved in the HSA $12 / 22 / 16$ associations and 


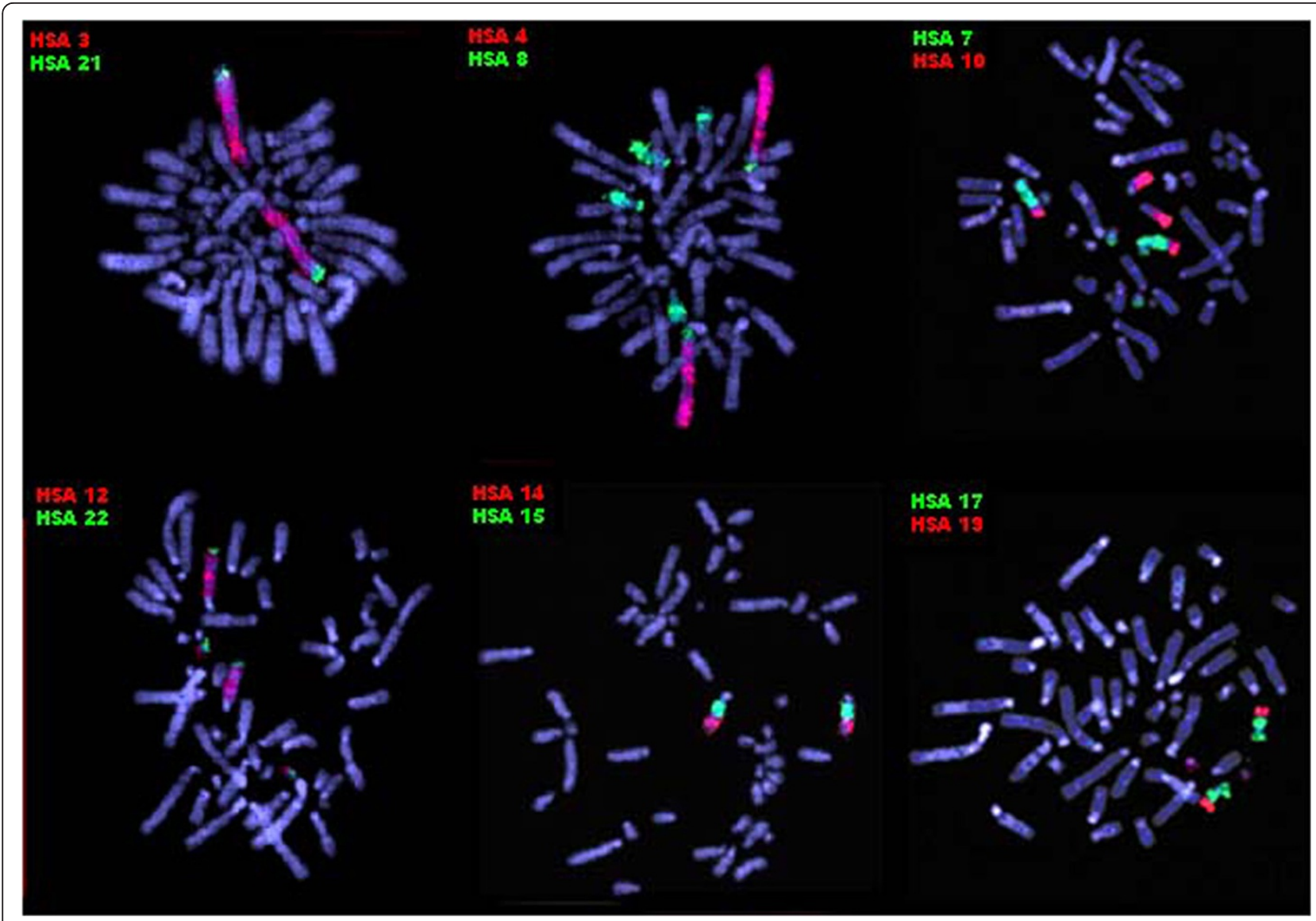

Figure 3 Partial metaphases of Bradypus torquatus $(2 n=50)$ after FISH with human chromosome-specific paints. The probes used are indicated for each experiment. The green signals were produced by biotin-labeled probes detected with FITC-conjugated avidin and the red signals, by digoxigenin-labeled probes detected with rhodamine-conjugated antidigoxigenin. The chromosomes were counterstained with DAPI.

the fissions of HSA 3 and 4 in both species. Our results coupled with previously reported data $[31,46]$ indicate that $B$. variegatus and B. tridactylus have more similar karyotypes than each of them has to B. torquatus, sharing even the derived HSA $12 / 22 / 16$ association. These results corroborate the recent published Bradypus molecular phylogeny, which indicated $B$. torquatus as a basal lineage within the genus [47]. The divergence

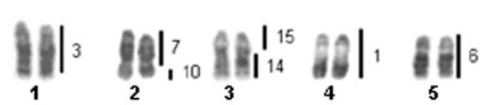

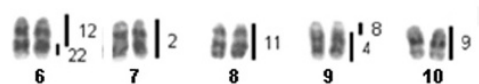

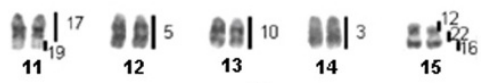

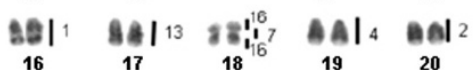

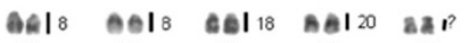

$$
\begin{aligned}
& \begin{array}{lllll}
21 & 22 & 23 & 24 & 25
\end{array} \\
& \text { sะ } 19 \\
& \text { (a) } 26 \\
& \left.\right|_{X} ^{25} \times
\end{aligned}
$$

\begin{tabular}{|c|c|c|c|c|}
\hline ib & 10 & bb & 98 & 0 \\
\hline & 2 & & 4 & 5 \\
\hline 90 & 88 & 10 & 00 & 00 \\
\hline & & & 9 & \\
\hline $\begin{array}{l}00 \\
11\end{array}$ & $\frac{91}{12}$ & 07 & 14 & \\
\hline 30 & $\begin{array}{l}00 \\
17\end{array}$ & $\begin{array}{l}8 \ell \\
18\end{array}$ & $\begin{array}{l}90 \\
19\end{array}$ & 20 \\
\hline 21 & $\begin{array}{c}00 \\
22\end{array}$ & $\begin{array}{l}0 \\
23\end{array}$ & $\begin{array}{c}10 \\
24\end{array}$ & \\
\hline
\end{tabular}

Figure 4 Correspondence between human chromosomes and (a) the G-banded karyotype of a male Bradypus variegatus ( $2 \mathrm{n}=54)$; (b) Cbanded karyotype of a male $\boldsymbol{B}$. variegatus. Each sloth chromosome segment was painted by the human chromosome indicated to the right. 


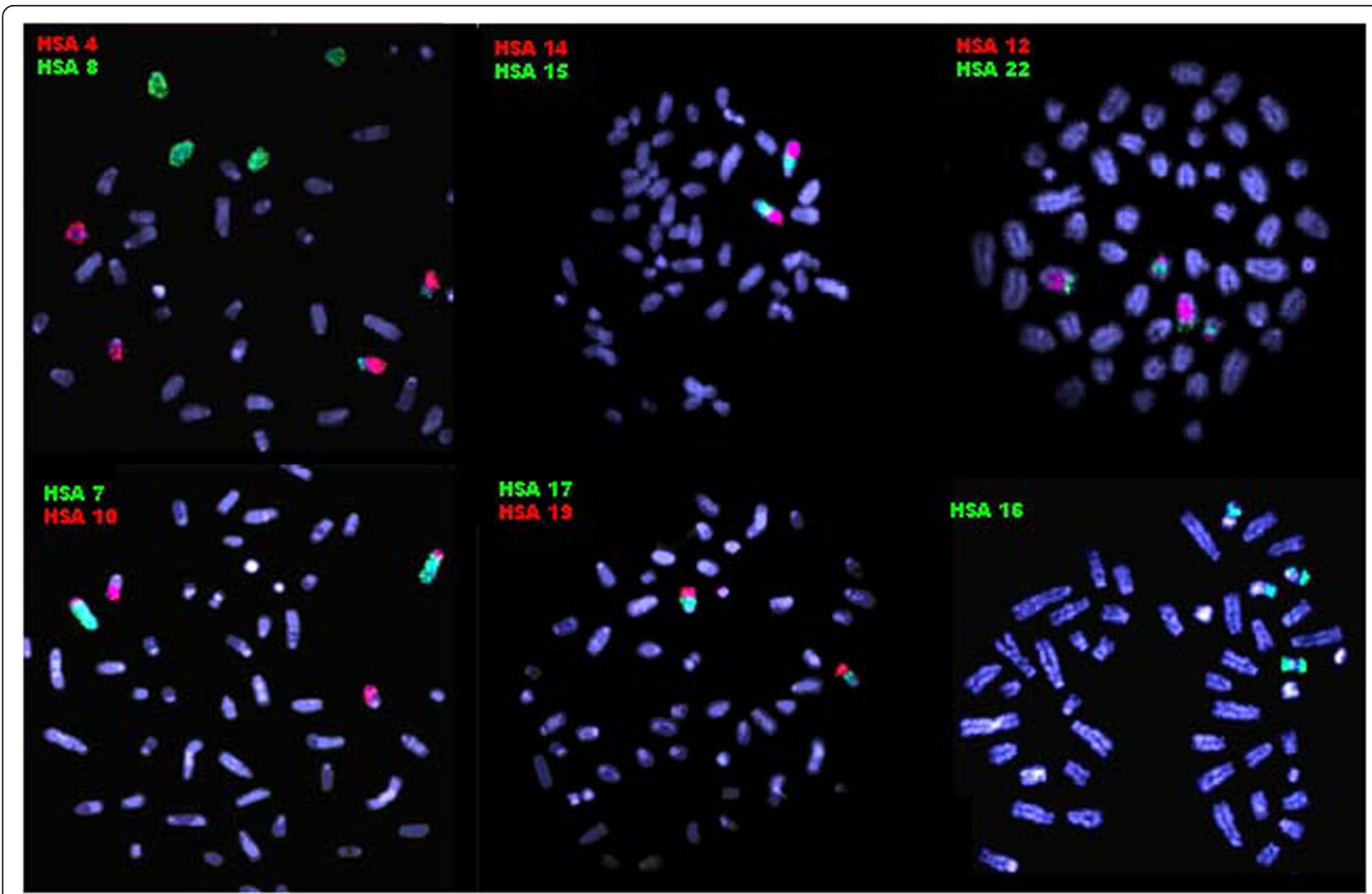

Figure 5 Partial metaphases of Bradypus variegatus $(2 n=54)$ after FISH with human chromosome-specific paints. The probes used are indicated for each experiment. The green signals were produced by biotin-labeled probes detected with FITC-conjugated avidin and the red signals, by digoxigenin-labeled probes detected with rhodamine-conjugated antidigoxigenin. The chromosomes were counterstained with DAPI.

between $B$. torquatus and the remaining Bradypus species occurred around 12 mya, B. tridactylus and B. variegatus being sister species, which diverged 6 mya. This finding gives some support to the notion that $B$. torquatus may be a different genus, as already suggested on the basis of morphological and molecular analyses $[50,51]$.

\section{Suborder Folivora (sloths)}

In sloths, the ancestral association HSA 16/19 was previously detected in C. hoffmanni [36]. This association was absent in $C$. didactylus [46] and we did not observe it in B. torquatus, B. variegatus or B. tridactylus. The absence of this ancestral Eutherian association in four sloth species is noteworthy because it is present in the great majority of placental mammals. This association may have been lost in the common ancestor of the genus Bradypus and in the lineage of $C$. didactylus or it may have disappeared in the common ancestor of the sloths and latter reappeared in the C. hoffmanni lineage. HSA $16 \mathrm{q} / 19 \mathrm{q}$ is the only Eutherian ancestral association derived from centric fusion [46]. Breakpoints in centromeric regions tend to be recurrent [52], which could explain the loss of the association twice, in Bradypus and in $C$. didactylus, or even its reappearance in $C$. hoffmanni, in the case that it was lost in a common ancestor of all the sloths.

No chromosome synapomorphy uniting the two genera of sloths was detected. This may indicate that no significant chromosome rearrangements accompanied the divergence of the suborder Folivora or that they do not share a recent common ancestor. Phylogenetic analysis based on morphological data of both extinct and extant species confirmed the grouping of Choloepus sloths to the Megalonychidae and placed Bradypus as the sister-taxon of all remaining sloths [26,27]. Molecular phylogenetic studies also indicated that each extant sloth species shares a more recent common ancestor with an extinct ground sloth species than with each other [50,53-55]. Other molecular phylogenetic studies including only extant sloth species indicated a very ancient divergence and estimated the separation between the two modern genera at 21 mya, supporting a taxonomic distinction at a high rank [3,25].

B. torquatus and C. hoffmanni, which have the lowest diploid numbers among the sloths, have the most 


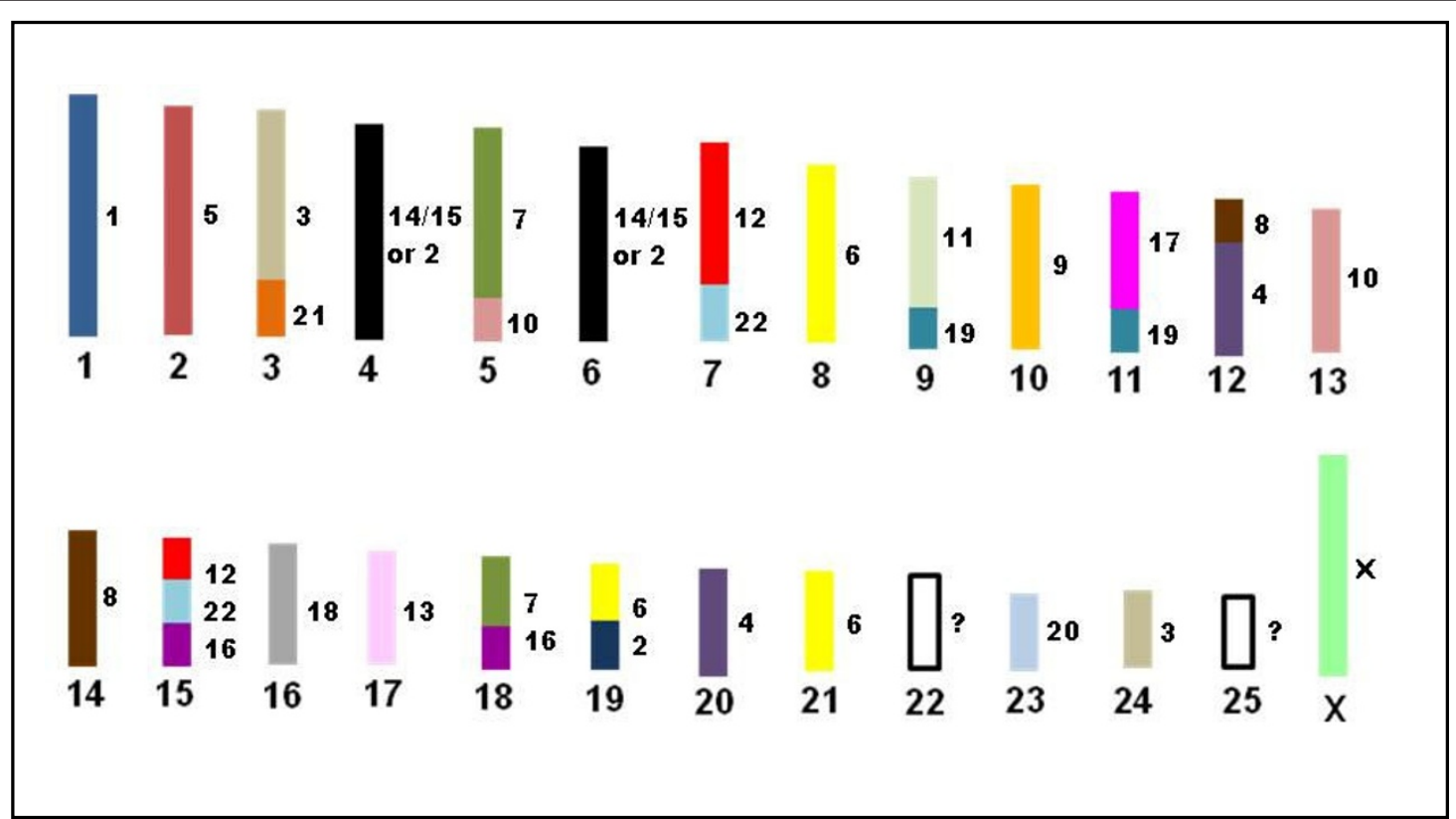

(a)

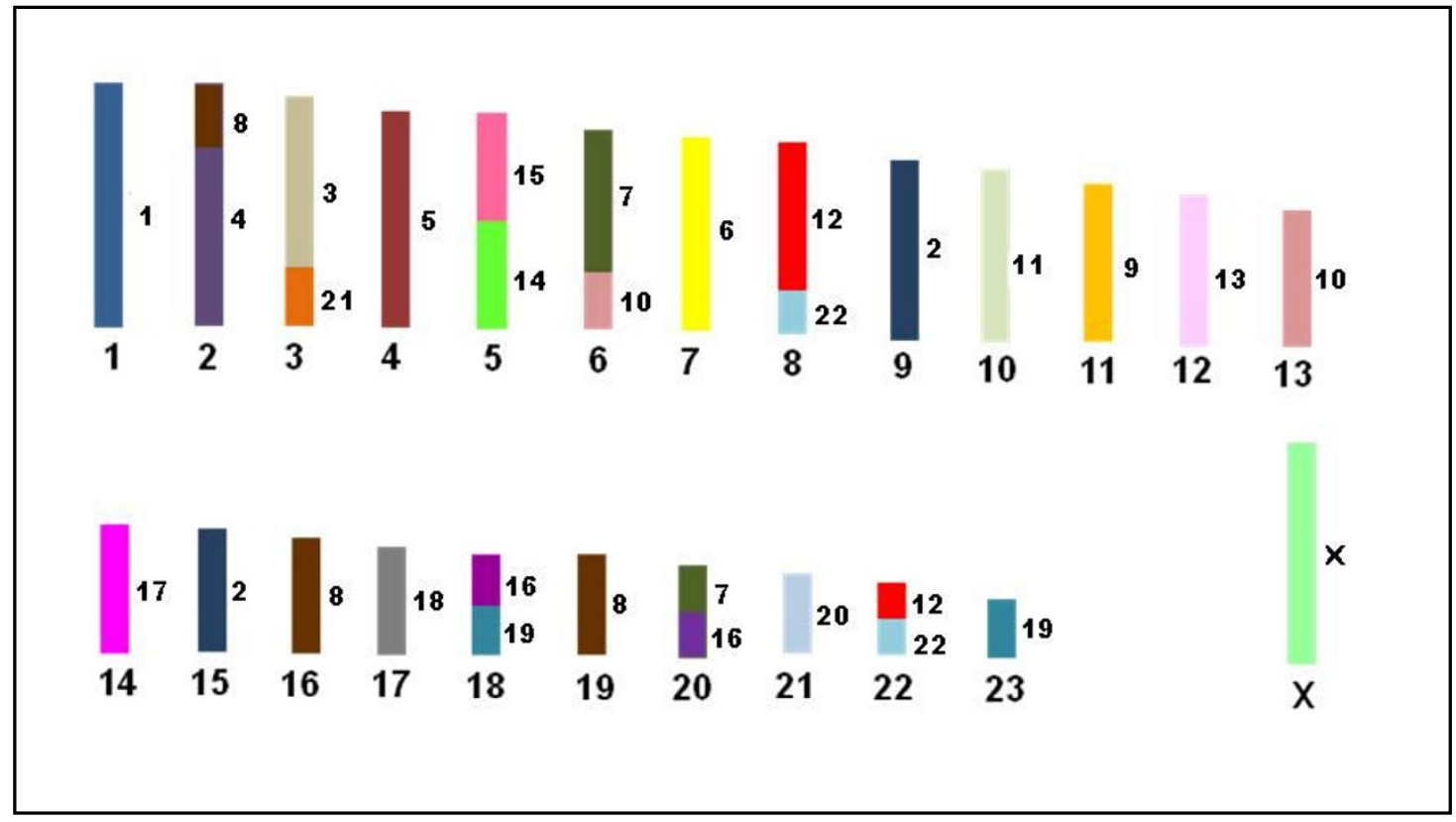

(b)

Figure 6 Schematic representation of the correspondence of human chromosomes to those in (a) B. tridactylus karyotype $(2 \mathrm{n}=52$ ) and (b) the proposed ancestral Xenarthran karyotype (AXK), with $\mathbf{2 n}=\mathbf{4 8}$. The human chromosomes are represented by the numbers on the right and by the color code.

conserved karyotypes in relation to those proposed as ancestral to Eutheria. They retain intact HSA 1, 3 and 4, each split into two blocks in B. variegatus and $C$. didactylus. A strong correlation between the maintenance of the ancestral chromosome corresponding to HSA 1 and low genomic evolution rates, exemplified by 
dolphins and humans was stressed by [43]. This is indeed the case of $B$. torquatus and $C$. hoffmanni that show the most conserved karyotypes in relation to a putative common ancestral Eutherian karyotype among sloths [36].

\section{Order Pilosa (anteaters and sloths)}

The division of HSA 12 in two blocks seems common to the order Pilosa (anteaters and sloths), while this chromosome is represented by three blocks in two species of armadillos [36,45]. Two pairs corresponding to HSA 12 are present in the karyotypes of most placental mammals and in the proposed ancestral Eutherian karyotypes [42,43]. The division of this human chromosome in three blocks in the armadillos is thus derived, whereas its presence in two segments in Pilosa is a symplesiomorphy. The monophyly of the order Pilosa is strongly supported by molecular data $[2,3,5]$, but chromosomal synapomorphies were not detected in the group, suggesting that the divergence of the clade was not accompanied by important chromosome rearrangements.

\section{Ancestral Xenarthran karyotype}

Besides the three Bradypus species discussed herein, five other species of Xenarthra were analyzed after painting with human chromosomes: Tamandua tetradactyla (lesser anteater), Dasypus novemcinctus (nine-banded armadillo), Euphractus sexcinctus (six-banded armadillo), Choloepus hoffmanni (Hoffmann's two-toed sloth), and C. didactylus (two-toed sloths) [36,45,46]. Our results together with those previously reported for other Xenarthra show some shared features among all the studied species: (a) the conservation of HSA 9, 13, 17, 18, 20 and X, (b) two pairs sharing homology with HSA 19 and 22 and (c) the presence of the ancestral Eutherian associations HSA $3 / 21,4 / 8,7 / 16,12 / 22$ and $14 / 15$ and (d) three chromosome pairs labeled by HSA 8 (Table 1).

Based on the comparisons of the karyotypes of species from the four families of Xenarthra among themselves or with the human karyotype and taking into account the karyotypes of outgroups, we propose an ancestral karyotype for the supraorder Xenarthra (AXK), with $2 \mathrm{n}$ $=48$ (Figure 6b). This karyotype contains: (a) the associations HSA 3/21, 4/8, 7/10, 7/16, 12/22 (2x), 14/15 and 16/19, (b) the conserved chromosomes HSA 1, 3, 4, $5,6,9,11,13,14,15,17,18,20,21$ and $\mathrm{X}$, (c) two pairs homologous to HSA 2, 7, 10, 12, 16, 19 and 22 and (d) three pairs homologous to HSA 8.

Some chromosomes or chromosome associations of $C$. didactylus (CDI 7, 8, 10, 14, 17, 24, 29, 3/31, 5/13b, 6/ $22,9 / 25$ and 26/27) were suggested as ancestral for Xenarthra, based on their presence in at least one Pilosa species and the outgroup, the six-banded armadillo
E. sexcinctus [31]. These chromosomes correspond to, respectively, HSA 1a, 9, 1b, 17, 13, 20, 7/16, 11/19, 3/21, $7 / 10,5$, and 16/19. From these ancestral Xenarthran chromosomes, HSA 1 split into two and the HSA 11/19 association are not included in our hypothetical AXK. Instead, HSA 1 would have been conserved as a single chromosome in the ancestral complement, because it was conserved as such in the Eutherian ancestor and in three species of Xenarthra (C. hoffmanni, B. torquatus, and B. tridactylus), and must have been convergently split in the karyotypes of the other species of the group, as already demonstrated for other placental mammals [43]. We did not include the HSA 11/19 association in the proposed ancestral Xenarthran karyotype, because it is present in just two species of the group (B. tridactylus and E. sexcinctus), besides being absent from the karyotypes of the outgroups and from the proposed ancestral Eutherian. The remaining chromosomes suggested by [31] are also present in our hypothetical AXK.

The associations HSA 2/8 and 7/10 have been suggested as chromosome signatures of the supraorder Xenarthra $[45,46]$. These authors detected the association HSA $2 / 8$ in $C$. didactylus, $T$. tetradactyla and $E$. sexcinctus, but it has not been observed in any other species of the group, including $B$. torquatus, B. variegatus and B. tridactylus in the present study. We thus conclude that its presence in $C$. didactylus and $T$. tetradactyla, which present rearranged karyotypes when compared to other Xenarthra, probably results from convergence.

The association HSA 7/10 was reported in C. didactylus, T. tetradactyla and E. sexcinctus and, by inference, in B. tridactylus $[45,46]$. We also observed this association in the karyotypes of $B$. torquatus and B. variegatus. This association is thus present in species representing the four Xenarthra families analyzed to date and was not found in any other Eutherian order, which supports the proposition that it is a chromosome signature of Xenarthra [46]. From all the Xenarthra species analyzed with human chromosome-specific probes, HSA 7/10 was not detected only in C. hoffmanni and in D. novemcinctus [36]. Nevertheless, these authors noted that a small distal segment of the sloth chromosome painted by HSA 7 was not labeled by any other human probe. It is possible that the unlabeled region corresponds to HSA 10 and was not detected.

The splitting of HSA 8 in three blocks was also proposed as a chromosome synapomorphy of Xenarthra [36]. This characteristic was observed in the karyotypes of the two-toed sloths $C$. didactylus and C. hoffmanni, in the anteater T. tetradactyla and in the armadillos $D$. novemcinctus and E. sexcinctus $[36,45,46]$. We also observed three HSA 8 labeled chromosome pairs in $B$. torquatus and B. variegatus, and this feature is also 
possibly present in $B$. tridactylus, which lends further support to this being a synapomorphy.

An ancestral Xenarthran karyotype with $2 n=54$, similar to the complement of E. sexcinctus $(2 \mathrm{n}=58)$ was suggested by [45]. The differences in relation to our proposed AXK are: chromosomes HSA 1, 4 and 6, which we considered as conserved, would be divided into two blocks; the association $2 / 8$ would be present, and HSA 2 would be divided into three blocks, instead of two. As discussed above, we favor the presence of a conserved HSA 1 and the absence of the HSA 2/8 association in our proposed AXK. In the currently most accepted versions of the common ancestral eutherian karyotype (AEK), HSA 1, 4 and 6 are conserved and HSA 2 is divided into two $[42,43]$.

HSA 2 painted two chromosomes in the three Bradypus species, in C. hoffmanni and in T. tetradactyla, while three chromosomes were labeled by HSA 2 in $C$. didactylus, E. sexcinctus and possibly in D. novemcinctus. We thus believe that the current data favor the idea that HSA 2 was present as two chromosomes in a putative AXK, instead of three, as proposed by [45].

HSA 4 painted two chromosome segments in B. variegatus, B. tridactylus, D. novemcinctus and C. didactylus, only one chromosome in C. hoffmanni and B. torquatus, and was split into three in E. sexcinctus and T. tetradactyla $[36,45,46]$. Tamandua tetradactyla has a relatively rearranged karyotype, as already noted, thus leaving $E$. sexcinctus as the sole species to be considered. This supports our conclusion that HSA 4 was more likely divided into two in the common ancestor of Xenarthra.

HSA 6, considered conserved in the AEK, was intact in B. torquatus, B. variegatus and C. hoffmanni; it was found in two blocks in $C$. didactylus, D. novemcinctus, E. sexcinctus and T. tetradactyla and it was split into three blocks in B. tridactylus. With these data, we consider it still uncertain if this chromosome would be represented in the AXK by only one pair, as we propose, or as two blocks, as proposed by [45]. The analysis of additional Xenarthra species promise to shed some light on this issue. For this purpose, data on Dasypodidae will be especially relevant, as this family is still relatively poorly analyzed with chromosome painting: only two out of 21 species had their karyotypes painted.

Our proposed ancestral Xenarthran karyotype differs from that suggested as ancestral to all Eutheria, with $2 \mathrm{n}$ $=48[43,44]$ by the presence of the association HSA 7/ 10 and by the split of HSA 8 into three blocks, with only two corresponding blocks in the Eutherian ancestor.

The associations HSA $1 / 19$ and 5/21 were suggested as chromosome signatures of the supraorder Afrotheria [44,56-58]. With the identification of the HSA 7/10 association and the division of HSA 8 in three blocks,
Xenarthra becomes the second placental mammal supraorder to have chromosome features pointing to its monophyly. The fusion of the segments corresponding to human chromosomes 7 and 10 and the fission of the segments corresponding to HSA 8 must have occurred in a common Xenarthra ancestor. However, it should be noted that reciprocal chromosome painting, gene mapping or sequencing studies are needed to confirm that the same chromosome segments and breakpoints are involved in the rearrangements of different Xenarthra species.

\section{The base of the tree}

There is still controversy on which clade is on the base of the Eutherian phylogenetic tree, Afrotheria, Xenarthra or a combination of the two $[3,9,11,12,15,18,19,59]$. The HSA $1 / 19$ association was proposed as a synapomorphy uniting Afrotheria and Xenarthra [42]. This association was found in all the studied species of Afrotheria, but in Xenarthra it was only observed in the lesser anteater $T$. tetradactyla $[36,46]$, the species with the most rearranged karyotype of the group. Moreover, there is no evidence that this association is homologous in the two groups $[31,36,46,49]$. We did not observe the HSA $1 / 19$ association in the karyotypes of $B$. variegatus and $B$. torquatus and it does not seem to be present in B. tridactylus. Thus, there are no good data to support the hypothesis that the $1 / 19$ association is a shared chromosomal characteristic uniting Afrotheria and Xenarthra.

In silico comparisons of the genomes of the marsupial Monodelphis domestica and the chicken Gallus gallus with the human genome (Ensembl) reveal an association between HSA 7q and 10p in the opossum chromosome 8 and in the chicken chromosome 1. The HSA 7/10 association seems to be a chromosome feature of Xenarthra, but reciprocal chromosome painting experiments should be performed to verify if homologous chromosome segments are involved in the association in Xenarthra and in the outgroups (marsupial and chicken). The HSA 10 segment involved in the association in Xenarthra is likely to be HSA $10 \mathrm{p}$, as is the case in the marsupial and the chicken. In the karyotypes proposed as ancestral in Eutheria, HSA 10 is split in two ancestral chromosomes (corresponding to HSA 10p and 10q). In Xenarthra the smallest segment corresponding to HSA 10 that probably represents HSA $10 p$, is associated with HSA 7. If the HSA 7/10 association in Xenarthra and in the outgroups proves to be homologous, it would be a strong indication that this association is ancestral to Eutheria and would support Xenarthra as basal for all placental mammals. The HSA 7/10 association present in the placental mammal ancestor would then have been lost in the lineage leading to the other placental mammals lineages, after the divergence of Xenarthra. If 
Afrotheria was the first supraorder to diverge from Eutheria or if Xenarthra and Afrotheria were sistergroups, $[15,18,19,21]$, then the HSA $7 / 10$ association would have been lost in the Afrotheria lineage and in the lineage leading to the remaining groups of Eutheria.

After chromosome painting with human probes in species of Xenarthra, the hypothesis that this supraorder is the basal group of Eutheria could not be discarded, as species of the group showed karyotypes very similar to those proposed as ancestral for Eutheria [36]. These data gained further support from the demonstration of two retropositions present in the genomes of all Eutherian clades, to the exclusion of Xenarthra [60].

\section{Conclusions}

Our analysis of chromosome painting in three-toed sloths allowed the proposition of a putative Ancestral Xenarthran Karyotype (AXK) and its comparison with the current versions of the Ancestral Eutherian Karyotype (AEK). We suggest that the association HSA 17/19 is a chromosome signature of the genus Bradypus. The association HSA 7/10 and the division of HSA 8 in three blocks would be chromosome features linking all Xenarthra and would be responsible for the differences between the AEK and the AXK. Recent work with chromosome e-painting comparing the genome sequences of Monodelphis domestica and Gallus gallus with the human genome (Ensembl) have already revealed some associations that could be ancestral to all these taxa. Further analyses combining molecular cytogenetics and genome sequencing will ultimately help to define which chromosome features are symplesiomorphic or synapomorphic for different groups.

\section{Methods}

Our sample consisted of animals from Brazil: one male Bradypus torquatus $(2 \mathrm{n}=50)$ from Santa Luzia, state of Bahia, one female $B$. variegatus $(2 \mathrm{n}=54)$ from Itabuna, state of Bahia, and two males of B. variegatus $(2 \mathrm{n}=54)$, one from Itapecerica da Serra and another from the city of São Paulo, both in the state of São Paulo. The material was collected with a license from the Instituto Brasileiro do Meio Ambiente e dos Recursos Naturais Renováveis (IBAMA, license 032/2005-CGFAU/LIC). Chromosome preparations were obtained from peripheral blood and fibroblasts cultures following conventional methods. G-banding was carried out according to [61] and C-banding was performed according to [62].

Human chromosome-specific probes were obtained by flow sorting, amplified and labeled by degenerate oligonucleotide PCR (DOP-PCR) as already described [44]. The interspecific fluorescent in situ hybridization (FISH) experiments were performed with a mixture of $1 \mu \mathrm{g}$ of the biotin or digoxigenin labeled probes pre-annealed with $1 \mu \mathrm{g}$ of Human Cot-1 DNA (Invitrogen) and resuspended in $15 \mu \mathrm{l}$ of hybridization buffer (formamide $50 \%$, 2xSSC, $40 \mathrm{mM}$ phosphate buffer). The probe mixtures were denatured at $98^{\circ} \mathrm{C}$ for 10 minutes and reannealed at $37^{\circ} \mathrm{C}$ for 30 minutes before hybridization.

The sloths chromosome preparations were treated for one hour in $2 \times S S C$ at $37^{\circ} \mathrm{C}$ and denatured at $72^{\circ} \mathrm{C}$ for two minutes. Hybridizations were carried out for seven days at $37^{\circ} \mathrm{C}$. Post-hybridization washes and immunodetection were performed as previously described [44] and the slides were mounted with Vectashield Mounting Medium (Vector Laboratories) and $0.8 \mathrm{ng} / \mu \mathrm{l}$ DAPI (Sigma-Aldrich Inc.). Analyses were performed under an epifluorescence Zeiss Axiophot 2 microscope equipped with a CCD camera and the images were processed with ISIS (Metasystems).

\section{Acknowledgements}

NFA was supported by a PhD scholarship from FAPESP (03/11518-9), and NMB, by postdoctoral scholarships from FAPESP (03/03212-7) and CAPESProdoc. The work was supported by grants from FAPESP to AMVM (CEPID Center for the Study of the Human Genome 98/14254-2), and from FAPEMIG (Processes CRA - APQ-00170-09 and PRONEX CBB-APQ-00336-09) to MS. The authors wish to thank Gary Stone for preparing the probes.

\section{Author details}

${ }^{1}$ Departamento de Genética e Biologia Evolutiva, Instituto de Biociências, Universidade de São Paulo, Rua do Matão 277, Cidade Universitária, São Paulo, SP 05408-090, Brazil. ²Departamento de Biologia Geral, Instituto de Ciências Biológicas, Universidade Federal de Minas Gerais, Avenida Antônio Carlos 6627, Belo Horizonte, MG 31270-901, Brazil. ${ }^{3}$ Department of Evolutionary Biology, University of Florence, Via del Proconsolo 12, Florence 50122, Italy.

\section{Authors' contributions}

NFA and AMVM conceived and designed the experiments. NFA and AM performed the experiments. NMB collected specimens. RS and AMVM contributed reagents/materials and analysis tools. NFA, MS, AMVM and RS analyzed the data. MS and NFA wrote the paper. AMVM, NMB and RS revised the paper. All the authors read and approved the final manuscript.

\section{Competing interests}

The authors declare that they have no competing interests.

Received: 25 September 2011 Accepted: 19 March 2012 Published: 19 March 2012

\section{References}

1. Glass B: History of classification and nomenclature in Xenarthra (Edentata). In The evolution and ecology of armadillos, sloths, and vermilinguas. Edited by: Montgomery G. Washington and London: Smithsonian University Press; 1985:51-64.

2. Delsuc F, Catzeflis F, Stanhope M, Douzery E: The evolution of armadillos, anteaters and sloths depicted by nuclear and mitochondrial phylogenies: Implications for the status of the enigmatic fossil Eurotamandua. Proc R Soc Lond B Biol Sci 2001, 268:1605-1615.

3. Delsuc F, Scally M, Madsen O, Stanhope M, de Jong W, Catzeflis F, Springer M, Douzery E: Molecular phylogeny of living xenarthrans and the impact of characters and taxon sampling on the placental tree rooting. Mol Biol Evol 2002, 19:1656-1671.

4. Engelman G: The phylogeny of Xenarthra. In The evolution and ecology of armadillos, sloths and vermilinguas. Edited by: Montgomery G. Washington and London: Smithsonian University Press; 1985:51-64.

5. Möller-Krull M, Delsuc F, Churakov G, Marker C, Superina M, Brosius J, Douzery E, Schmitz J: Retroposed elements and their flanking regions 
resolve the evolutionary history of xenarthran mammals (armadillos, anteaters, and sloths). Mol Biol Evol 2007, 24:2573-2582.

6. Murphy W, Eizirik E, Johnson W, Zhang Y, Ryder O, O'Brien S: Molecular phylogenetics and the origin of placental mammals. Nature 2001, 409:614-618.

7. Murphy W, Eizirik E, O'Brien S, Madsen O, Scally M, Douady C, Teeling E, Ryder O, Stanhope M, de Jong W, et al: Resolution of the early placental mammal radiation using Bayesian phylogenetics. Science 2001, 295:2348-2351.

8. Gardner A: Magnaorder Xenarthra Cope, 1889. In Mammals of South America, Marsupials, Xenarthrans, Shrews, and Bats. Volume 1. Edited by: Gardner A. Chicago and London: The University of Chicago Press; 2008:127-177.

9. Shoshani J, McKenna M: Higher taxonomic relationships among extant mammals based on morphology, with selected comparisons of results from molecular data. Mol Phylogenet Evol 1998, 9:572-584.

10. Amrine-Madsen H, Koepfli K, Wayne R, Springer M: A new phylogenetic marker, apolipoprotein $\mathrm{B}$, provides compelling evidence for eutherian relationships. Mol Phylogenet Evol 2003, 28:225-240.

11. Nikolaev S, Montoya-Burgos J, Margulies E, Rougemont J, Nyffeler B, Antonarakis S: Early history of mammals is elucidated with the ENCODE multispecies sequencing data. PLoS Genet 2007, 3:e2.

12. Nishihara $\mathrm{H}$, Okada N, Hasegawa M: Rooting the eutherian tree: the power and pitfalls of phylogenomics. Genome Biol 2007, 8:R199.

13. Scally M, Madsen O, Douady C, de Jong W, Stanhope M, Springer M: Molecular evidence for the major clades of placental mammals. J Mamm Evol 2001, 8:239-277.

14. Waddell $\mathrm{P}$, Kishino $\mathrm{H}$, Ota R: A phylogenetic foundation for comparative mammalian genomics. Genome Inform 2001, 12:141-154.

15. Hallström B, Kullberg M, Nilsson M, Janke A: Phylogenomic data analyses provide evidence that Xenarthra and Afrotheria are sister groups. Mol Biol Evol 2007, 24:2059-2068.

16. Lin $Y$, McLenachan $P$, Gore A, Phillips $M$, Ota R, Hendy M, Penny D: Four new mitochondrial genomes and the increased instability of evolutionary trees of mammals from improved taxon sampling. Mol Biol Evol 2002, 19:2060-2070.

17. Madsen O, Scally M, Douady C, Kao D, DeBry R, Adkins R, Amrine H, Stanhope M, de Jong W, Springer M: Parallel adaptative radiations in two major clades of placental mammals. Nature 2001, 409:610-614.

18. Murphy W, Pringle T, Crider T, Springer M, Miller W: Using genomic data to unravel the root of the placental mammal phylogeny. Genome Res 2007, 17:413-421.

19. Prasad A, Allard M, Program NCS, Green E: Confirming the phylogeny of mammals by use of large comparative sequence data sets. Mol Biol Evol 2008, 25:1795-1808.

20. Waddell P, Cao Y, Hauf J, Hasegawa M: Using novel phylogenetic methods to evaluate mammalian mtDNA, including amino acid-invariant sites-LogDet plus site stripping, to detect internal conflicts in the data, with special reference to the positions of hedgehog, armadillo, and elephant. Syst Biol 1999, 48:31-53.

21. Waters P, Dobigny G, Waddell P, Robinson T: Evolutionary history of LINE1 in the major clades of placental mammals. PLoS One 2007, 2:e158.

22. Wetzel R: The identification and distribution of recent Xenarthra (Edentata). In The evolution and ecology of armadillos, sloths and vermilinguas. Edited by: Montgomery G. Washington and London: Smithsonian Institution Press; 1985:5-21.

23. Anderson R, Handley C Jr: A new species of three-toed sloth (Mammalia: Xenarthra) from Panama, with a review of the genus Bradypu. Proc Biol Soc Wash 2001, 114:1-33.

24. The IUCN Red List of Threatened Species. Version 2011.1. [http://www. iucnredlist.org].

25. Delsuc F, Vizcaino S, Douzery E: Influence of Tertiary paleoenvironmental changes on the diversification of South American mammals: A relaxed molecular clock study within Xenarthrans. BMC Evol Biol 2004, 4:11.

26. Gaudin T: Phylogenetic relationships among sloths (Mammalia, Xenarthra, Tardigrada): the craniodental evidence. Zool J Linn Soc 2004, 140:255-305.

27. Pujos F, Iulis G, Argot C, Werdelin L: A peculiar climbing Megalonychidae from the Pleistocene of Peru and its implication for sloth history. Zool $J$ Linn Soc 2007, 149:179-235.
28. Barroso CM, Seuánez H: Chromosome studies on Dasypus, Euphractus and Cabassous genera (Edentata: Dasypodidae). Cytobios 1991, 68:179-196.

29. Jorge W, Meritt DA Jr, Benirschke K: Chromosome studies in Edentata. Cytobios 1978, 18:157-172.

30. Pereira H, Jorge W, Teixeira da Costa M: Chromosome study of anteaters (Myrmecophagidae, Xenarthra): a preliminary report. Genet Mol Biol 2004, 27:391-394.

31. Dobigny G, Yang F, O'Brien P, Volobouev V, Kovacs A, Pieczarka J, FergusonSmith M, Robinson T: Low rate of genomic repatterning in Xenarthra inferred from chromosome painting data. Chromosome Res 2005, 13:651-663.

32. Lizarralde M, Bolzán A, Poljak S, Pigozzi M, Bustos J, Merani M: Chromosomal localization of the telomeric (TTAGGG)n sequence in four species of armadillo (Dasypodidae) from Argentina: an approach to explaining karyotype evolution in the Xenarthra. Chromosome Res 2005, 13:777-784.

33. Jorge W: Estudo cromossômico de algumas espécies da ordem Edentata. Livre Docência Botucatu: UNESP; 1981.

34. Jorge W, Orsi-Souza A, Best R: The somatic chromosomes of Xenarthra. In The evolution and ecology of armadillos, sloths and vermilinguas. Edited by: Montgomery G. Washington and London: Smithsonian University Press; 1985:429-437.

35. Kovacs A, Révay T, Tardy P, Mezosi L: $2 n=65$ karyotype in a two-toed sloth (Choloepus didactylus, L). Ann Genet 2001, 44-43.

36. Svartman M, Stone $G$, Stanyon R: The ancestral Eutherian karyotype is present in Xenarthra. PLoS Genet 2006, 42:1006-1011.

37. Corin-Frédéric J: Les formules gonosomiques dites aberrates chez les mammifères euthériens. Chromosoma 1969, 27:268-287.

38. Goldschmidt B, Almeida J, Oliveira V: Visualization of nuclear organizer regions in sloths (Bradypus variegatus and Scaepus torquatus). Rev Bras Genet 1995, 18:111-113.

39. Jorge W, Pinder L: Chromosome study on the maned sloth Bradypus torquatus (Bradypodidae, Xenarthra). Cytobios 1990, 62:21-25.

40. Goldschmidt B, Almeida J: Cytogenetic studies in sloths (Bradypus variegatus). Rev Bras Genet 1993, 16:939-948.

41. Rokas A, Holland W: Rare genomic changes as a tool for phylogenetics. Trends Ecol Evol 2000, 15:454-459.

42. Ferguson-Smith M, Trifonov V: Mammalian karyotype evolution. Nat Rev Genet 2007, 8:950-962.

43. Murphy W, Frönicke L, O'Brien S, Stanyon R: The origin of human chromosome 1 and its homologs in placental mammals. Genome Res 2003, 13:1880-1888.

44. Svartman M, Stone G, Page J, Stanyon R: A chromosome painting test of the basal Eutherian karyotype. Chromosome Res 2004, 12:45-53.

45. Liu Y, Ye J, Fu B, Ng B, Wang J, Su W, Yang F, Nie W: Molecular cytogenetic characterization of the genome organization of the 6banded armadillo (Euphractus sexcinctus). Cytogenet Genome Res 2010, 132:31-40.

46. Yang F, Graphodatsky A, Li T, Fu B, Dobigny G, Wang J, Perelman P. Serdukova N, Su W, O'Brien P, et al: Comparative genome maps of the pangolin, hedgehog, sloth, anteater and human revealed by crossspecies chromosome painting: further insight into the ancestral karyotype and genome evolution of eutherian mammals. Chromosome Res 2006, 14:283-296.

47. de Moraes-Barros N, Silva J, Morgante J: Morphology, molecular phylogeny, and taxonomic inconsistencies in the study of Bradypus sloths (Pilosa: Bradypodidae). J Mammal 2011, 92:86-100.

48. Huang L, Nesterenko A, Nie W, Wang J, Su W, Graphodatsky A, Yang F: Karyotype evolution of giraffes (Giraffa camelopardalis) revealed by cross-species chromosome painting with Chinese muntjac (Muntiacus reevesi) and human (Homo sapiens) paints. Cytogenet Genome Res 2008, 122:132-138.

49. Yang F, Alkalaeva E, Perelman P, Pardini A, Harrison W, O'Brien P, Fu B, Graphodatsky A, Ferguson-Smith M, Robinson T: Reciprocal chromosome painting among human, aardvark, and elephant (superorder Afrotheria) reveals the likely eutherian ancestral karyotype. PNAS 2003, 100:1062-1066.

50. Barros M, Sampaio I, Schneider H: Phylogenetic analysis of $16 \mathrm{~S}$ Mitochondrial DNA data in sloths and anteaters. Genet Mol Biol 2003, 26:5-11. 
51. Wetzel R, Ávila-Pires F: Identification and distribution of the recent sloths of Brazil (Edentata). Rev Bras Biol 1980, 40:831-836.

52. Murphy W, Larkin D, Everts-van der Wind A, Bourque G, Tesler G, Auvil L, Beever J, Chowdhary B, Galibert F, Gatzke L, et al: Dynamics of mammalian chromosome evolution inferred from multispecies comparative maps. Science 2005, 309:613-617.

53. Greenwood A, Castresana J, Feldmayer-Fuchs G, Paabo S: A molecular phylogeny of two extinct sloths. Mol Phylogenet Evol 2001, 18:94-103.

54. Höss M, Dilling A, Currant A, Paabo S: Molecular phylogeny of the extinct ground sloth Mylodon darwinii. Proc Natl Acad Sci 1996, 93:181-185.

55. Poinar H, Kuch M, McDonald G, Martin P, Pääbo S: Nuclear gene sequences from a late Pleistocene sloth soprolite. Curr Biol 2003, 13:1150-1152.

56. Frönicke L, Wienberg J, Stone G, Adams L, Stanyon R: Towards the delineation of the ancestral Eutherian genome organization: Comparative genome maps of human and the African elephant (Loxodonta african) generated by chromosome painting. Proc $R$ Soc Lond B Biol Sci 2003, 270:1331-1340.

57. Kellogg M, Burkett S, Dennis T, Stone G, Gray B, McGuire P, Zori R, Stanyon R: Chromosome painting in the manatee supports Afrotheria and Paenungulata. BMC Evol Biol 2007, 7:6.

58. Ruiz-Herrera A, Robinson T: Chromosomal instability in Afrotheria: fragile sites, evolutionary breakpoints and phylogenetic inference from genome sequence assemblies. BMC Evol Biol 2007, 7:199.

59. Springer M, Stanhope M, Madsen O, de Jong W: Molecules consolidate the placental mammal tree. Trends Ecol Evol 2004, 19:430-438.

60. Kriegs J, Churakov G, Kiefmann M, Jordan U, Brosius J, Schmitz J: Retroposed elements as archives for the evolutionary history of placental mammals. PLoS Biol 2006, 4(4):e91.

61. Seabright M: A rapid banding technique for human chromosomes. Lancet 1971, 2(7731):971-972.

62. Sumner AT: A simple technique for demonstrating centromeric heterochromatin. Exp Cell Res 1972, 75(1):304-306.

63. Delsuc F, Superina M, Tilak M, Douzery E, Hassanin A: Molecular phylogenetics unveils the ancient evolutionary origins of the enigmatic fairy armadillos. Mol Phylogenet Evol 2012, 62:673-680.

doi:10.1186/1471-2148-12-36

Cite this article as: Azevedo et al:: Chromosome painting in three-toed sloths: a cytogenetic signature and ancestral karyotype for Xenarthra. BMC Evolutionary Biology 2012 12:36.

\section{Submit your next manuscript to BioMed Central and take full advantage of:}

- Convenient online submission

- Thorough peer review

- No space constraints or color figure charges

- Immediate publication on acceptance

- Inclusion in PubMed, CAS, Scopus and Google Scholar

- Research which is freely available for redistribution

Submit your manuscript at www.biomedcentral.com/submit 